\title{
CNT-based Materials as Electrodes for Flexible Supercapacitors
}

\author{
Gabriela Queirós ${ }^{1}$, Natalia Rey-Raap², Clara Pereira ${ }^{3}$, \\ Manuel Fernando R. Pereira ${ }^{4}$ \\ 1LAQV@REQUIMTE, Department of Chemistry and Biochemistry, Faculty of Sciences, \\ University of Porto, Rua do Campo Alegre, 4169-007 Porto, Portugal; LSRE-LCM, Department \\ of Chemical Engineering, Faculty of Engineering, University of Porto, Rua Dr. Roberto Frias, \\ 4200-465 Porto, Portugal (gabrielaq@fe.up.pt) ORCID 0000-0002-6030-970X; ²LSRE-LCM, \\ Department of Chemical Engineering, Faculty of Engineering, University of Porto, Rua Dr. \\ Roberto Frias, 4200-465 Porto, Portugal; Department of Physical and Analytical Chemistry, \\ Oviedo University-CINN, 33006, Oviedo, Spain (nataliarey@fe.up.pt) ORCID 0000-0002-5003- \\ 0035; 3 LAQV@REQUIMTE, Department of Chemistry and Biochemistry, Faculty of Sciences, \\ University of Porto, Rua do Campo Alegre, 4169-007 Porto, Portugal (clara.pereira@fc.up.pt) \\ ORCID 0000-0001-9224-1917; “'LSRE-LCM, Department of Chemical Engineering, Faculty of \\ Engineering, University of Porto, Rua Dr. Roberto Frias, 4200-465 Porto, Portugal \\ (fpereira@fe.up.pt) ORCID 0000-0002-5447-2471
}

\begin{abstract}
Supercapacitors are energy storage devices that have received much interest in the past decade. These devices have unique characteristics, such as high energy density, fast charging, extensive life cycle, and excellent stability. Currently, wearable electronic gadgets have appeared as an interesting application for flexible supercapacitors, in which lightness and flexibility of the electrodes are two of the most important properties. In addition, the materials used as electrodes severely affect the behavior of these devices. Carbon nanomaterials are the most proficient and most studied electrode materials in flexible supercapacitors. Among them, carbon nanotubes (CNTs) have been extensively studied owing to their excellent mechanical and electrical properties. Therefore, this short review focuses on the new progress in the use of CNT materials as electrodes in flexible energy storage devices.
\end{abstract}

Author Keywords. Supercapacitors, Gel Polymer Electrolytes, Carbon Nanotubes, Energy Storage, Flexibility.

Type: Review Article

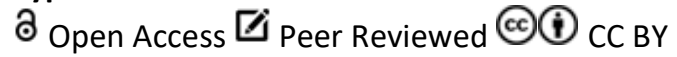

\section{Introduction}

Over the years there has been a growing concern with the environment and the search for renewable energy sources that contribute to the reduction of greenhouse gas emissions in the atmosphere. Besides, there is a need for the development of efficient energy storage systems compatible with these environmental concerns. In this line, supercapacitors (SCs) are quite interesting devices to address these environmental and energy topics, as they can store energy via environmentally friendly processes with high power density, quick charge, and extended life cycle. One of the main advantages of SCs is that they exhibit high energy density like batteries andhigh power density similarly to capacitors, being able to support a large number of charge-discharge cycles.

SCs are devices composed of two electrodes, an electrolyte and separator membrane, which are used in several applications such as medical appliances, transportation, electrical devices, and defense systems (Frackowiak 2007). However, conventional SCs have some limitations in 
applications such as wearable electronic gadgets due to safety and environmental problems, as they require cell designs with rigid and robust packaging to contain the electrolyte. Thus, flexible and wearable SCs are a key for smart devices integrated into garments, using a polymeric membrane or an ionic conductive gel as the separator, providing greater lightness and flexibility (Alipoori et al. 2020).

Alike in conventional SCs, the materials used as electrodes significantly influence the performance of flexible SCs. In recent years, textile-based electrodes have been produced by introducing carbon-based materials, metal oxides, and conductive polymers into fabrics or fibers, demonstrating improved electrochemical performance in flexible/wearable SCs. The most promising carbon electrode (nano)material for flexible SCs are carbon nanotubes, graphene, mesoporous carbon, and activated carbon owing to their large surface area, high electrochemical stability and exceptional mechanical and electrical properties. Among these materials, carbon nanotubes (CNTs) have gained great focus due to their excellent electrical conductivity and high tensile strength, derived from their atomic and surface chemical structure (Kumar et al. 2017). In fact, the number of scientific articles focused on CNTs for flexible SCs has increased over the past ten years, as shown in Figure 1. For this reason, this short review focus on the new advances in the application of CNT-based materials as electrodes in flexible SC devices. The first section will present the fundamental principles of operation and characteristics of SCs, focusing on the progress of flexible SCs using gel polymer electrolytes, and the second section is dedicated to CNT electrodes for flexible SCS.

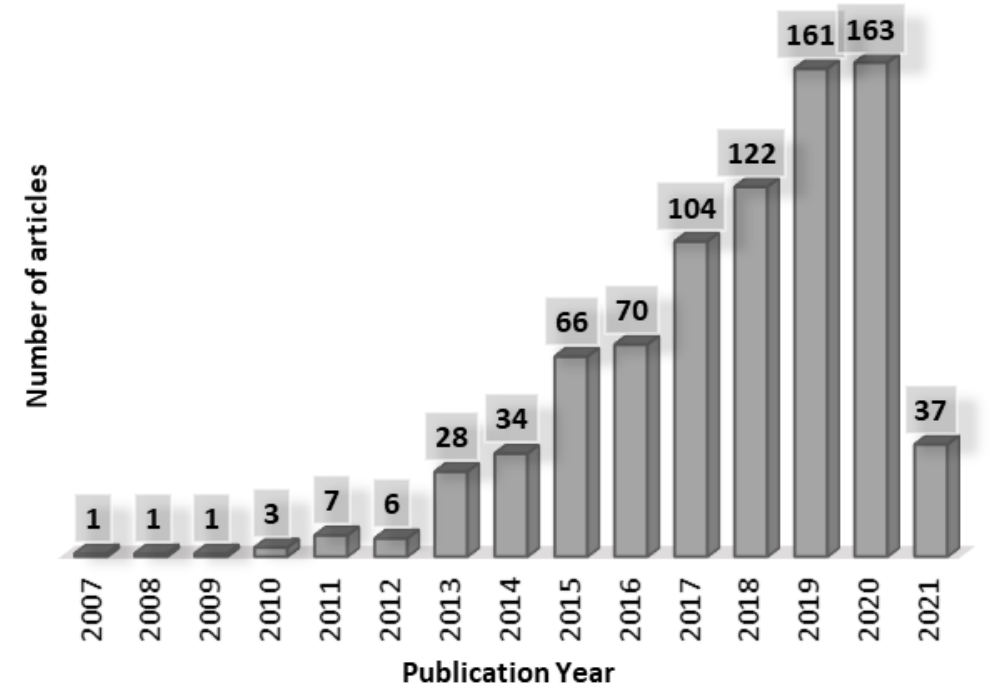

Figure 1: Number of articles published over the years about carbon nanotubes as electrode material in flexible SCs (Source: Scopus, Keywords:

"flexible supercapacitor" AND "carbon nanotubes")

\section{Flexible Supercapacitors}

SCs are devices involving two electrodes with high surface areas divided by a separator soaked in an electrolyte containing positive and negative ions as shown in Figure 2 (Alipoori et al. 2020). The phenomena involved in a typical SC are electrosorption of ions, near-surface reduction-oxidation reactions at the electrode/electrolyte interfaces (redox reactions), and intercalation of ions into the positive or negative electrode (Zhai et al. 2012). 


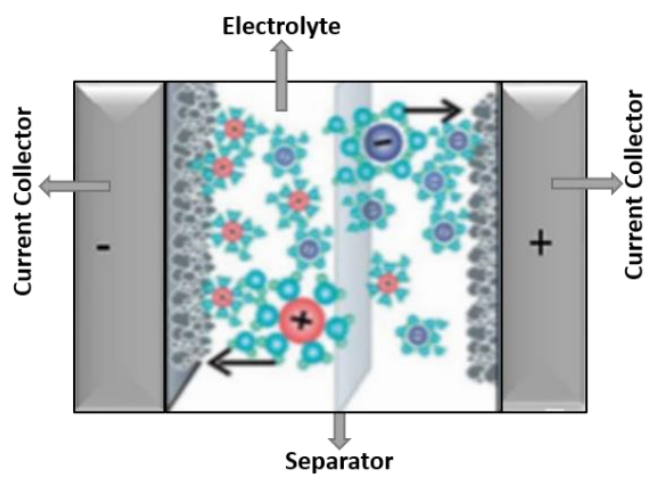

Figure 2: Scheme of the internal structure of a supercapacitor, adapted from Kumar et al. (2017); J. Varma et al. (2018)

The electrosorption of ions taking place at the electrode/electrolyte interface strongly defines the performance of a SC (Lota, Fic, and Frackowiak 2011), being possible to divide the SCs into 3 different groups based on the charge storage mechanism: Electrical Double Layer Capacitors (EDLCS), Pseudocapacitors, and Hybrid capacitors. EDLCs store charges at the electrode and electrolyte interface, avoiding the transfer of charge between them (non-Faradaic processes) (Liu et al. 2010). Carbon (nano)materials have been the most commonly used electrode materials in EDLCs. Contrarily, in pseudocapacitors the charge is transferred by reversible redox reaction(s) (Faradaic processes) on or near the electrode surface (Frackowiak 2007; Zhong et al. 2015). The pseudocapacitive electrode materials most commonly used are transition metal oxides and electrically conducting polymers. Finally, hybrid capacitors combine EDLCs and pseudocapacitive- or battery-type charge storage mechanisms (nonFaradaic and Faradaic processes) in a single device (Pereira and Pereira 2016).

Cyclic voltammetry (CV), galvanostatic charge-discharge tests (GCD), and electrochemical impedance spectroscopy (EIS) are the most common procedures used to evaluate the performance of SCs. The results obtained from these technique, give rise to values of energy and power density, which can be compared for different electrochemical energy storage devices using the Ragone plot shown in Figure 3 (this plot denotes the power density as a function of the energy density). The energy density is the quantity of energy stored per unit of mass, whereas power density represents the quantity of power per unit of mass. SCs and capacitors are recognized as high power density systems, while fuel cells and batteries are defined as high energy density systems (Yu et al. 2013; Miller and Burke 2008; Winter and Brodd 2004).

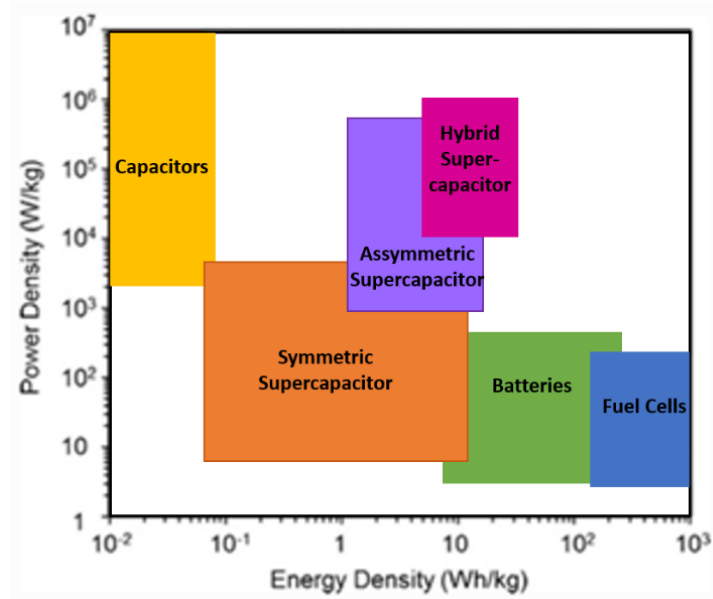

Figure 3: Ragone plot for different energy storage devices, adapted from Meng, Gall, and Irazoqui (2013); Choudhary et al. (2017) 
Comparatively to batteries and fuel cells, supercapacitors and capacitors have high power density $(10 \mathrm{~kW} / \mathrm{kg})$, fast charge-discharge cycles (within seconds), exceptional reversibility (90-95\%), extensive cycle life $\left(>1 \times 10^{5}\right)$, large coulombic efficiencies and operate safely (Zhao et al. 2011; Zhong et al. 2015). The life cycle is a significant factor to estimate the electrochemical behavior of a SC and depends on several aspects such as the nature of the electrolyte, electrode material, temperature, cell working voltage and GCD rate (Aziz et al. 2018).

Flexible SCs can have three device configurations: sandwich, in-plane, and cable-type (Figure 4). The most common configuration in flexible SCs is the sandwich assembly due to its simple design, low cost, and ease of mass production. The advantage of using the interdigital configuration in the plane is the ease of rapid ion transport between the two electrodes, providing higher power density. Finally, the cable-type configuration allows improving the mechanical property for applications in mobile and clothing devices (Zhu, Ni, and Li 2020).

The SCs assembly can be symmetric or asymmetric. Symmetric SCs have the same type of electrode as cathode and anode, while asymmetric SCs are assembled using two distinct electrodes. Asymmetric SCs generally reach higher operating voltages and capacitance than symmetric SCs. Therefore, in recent years, asymmetric forms have been studied to achieve the best electrochemical performance for flexible SCs.

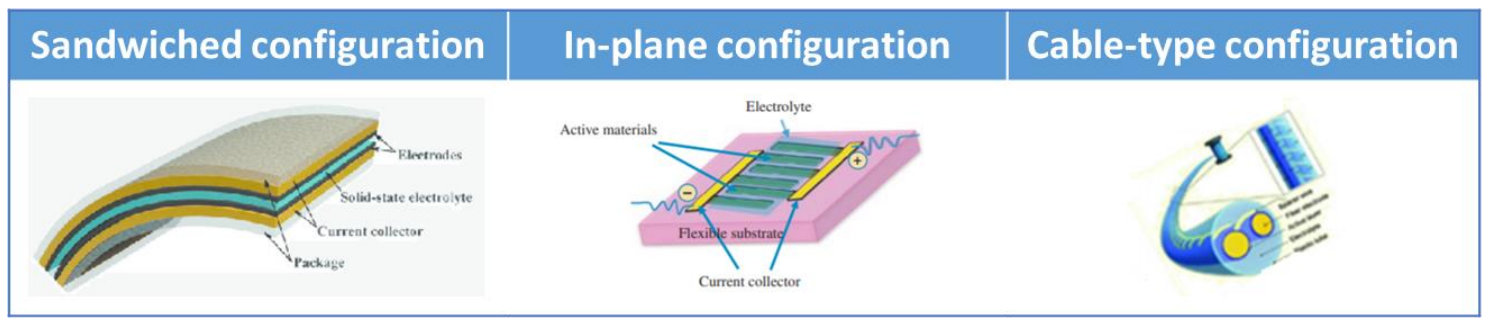

Figure 4: Schematic of flexible SCs assembled in various device configurations, adapted from Zhu, Ni, and Li (2020); Zhong et al. (2015); Dey and Kumar (2016)

Regarding the electrolyte, aqueous, organic, or gel polymer are commonly employed in SCs. An advantage of using polymeric gel electrolytes is that they allow the SCs to operate in a larger potential window while maintaining their electrochemical stability, unlike aqueous electrolytes where the operating voltage is restricted to $1.23 \mathrm{~V}$ because it is the electrolysis potential of water. In a flexible SC, liquid electrolytes are replaced by a gel polymer membrane, providing greater lightness and flexibility (Alipoori et al. 2020). Poly(ethylene oxide) (PEO), polyvinyl alcohol (PVA), poly(methyl methacrylate) (PMMA), poly(acrylonitrile) (PAN), poly(vinylidene fluoride) (PVDF) and poly(vinylidene fluoride-co-hexafluoro propylene) (HFP) are several examples of polymer matrix materials with relevance in the preparation of gel polymer electrolytes (Alipoori et al. 2020). In particular, PVA is an excellent candidate for flexible SCs because it has exceptional chemical stability, great mechanical properties, the capacity to form a transparent film and is non-toxic (Tu et al. 2018; Choudhury, Sampath, and Shukla 2009; Thakur et al. 2012; Choudhury et al. 2006). PVA has been widely employed as a porous matrix mixed with ionic conductive agents, like phosphoric acid, potassium hydroxide, or other ionic salts and liquids. These mixtures form solid-gel polymer electrolytes for allsolid-state SCs (Yang 2020). Polyvinyl alcohol-phosphoric acid $\left(\mathrm{PVA}-\mathrm{H}_{3} \mathrm{PO}_{4}\right)$ gel electrolyte shows higher specific capacitance than other electrolytes such as polyvinil alcohol-potassium hydroxide (PVA/KOH), polyvinil alcohol- sulfuric acid $\left(\mathrm{PVA} / \mathrm{H}_{2} \mathrm{SO}_{4}\right)$ and polyvinil alcoholpotassium chloride (PVA/KCl) (Vandana et al. 2020).

Viscosity, ionic conductivity and thermal properties of the electrolyte, surface area and electrical characteristics of the electrode material, and the interaction between them, are the 
main parameters that influence the behavior of a flexible SC, specifically in terms of capacitance, energy density, power density and life cycle (Alipoori et al. 2020). Hence, the development of innovative electrode materials is essential to obtain high-performance SCs. Carbon nanomaterials like activated carbon, graphene and CNTs have been commonly used in SCs due to their large specific surface areas, which are beneficial for electrolyte ions adsorption/desorption. For their application in flexible SCs, CNTs have many attractive properties like good mechanical strength and elasticity, and good electronic properties oscillating from semiconductors to metals (Segawa, Ito, and Itami 2016; Wen, Li, and Cheng 2016; Zeevi et al. 2016). Therefore, the next section is focused on the research performed to date about CNTs in flexible SCs.

\section{CNTs for Energy Storage}

Compared to traditional carbon materials, CNTs are more prone to form a porous network that can promote the movement of ions (Beidaghi and Gogotsi 2014). Besides, they can be more easily attached to the surface of several substrates (papers, plastic films and textiles) through van der Waals interaction or hydrogen bonds. These strong interactions ensure the excellent flexibility of the entire composite film (Zhao et al. 2020).

CNT electrode materials generally have EDLC-type behavior. EDLCs involving pure CNT films generally have a specific capacitance of less than $100 \mathrm{~F} / \mathrm{g}$. However, owing to the high electrical conductivity of CNTs, EDLCs based on CNT films perform better than those based on activated carbon, being advantageous for flexible electronic devices that require high power densities. In addition to the high conductivity and large specific area, CNT films provide high porosity for the incorporation of redox-active materials, which makes them powerful like high-performance flexible electrodes (Chen et al. 2015). In this way, hybrid capacitors arise by introducing pseudocapacitive materials in flexible CNT film electrodes to enlarge the capacitance. Thus, in this section, recent studies focused on CNTs combined with metal oxides, conducting polymers, or other carbon nanomaterials to increase the electrochemical behavior of flexible SCs will be detailed. Figure 5 shows the timeline of the most relevant works in this application.

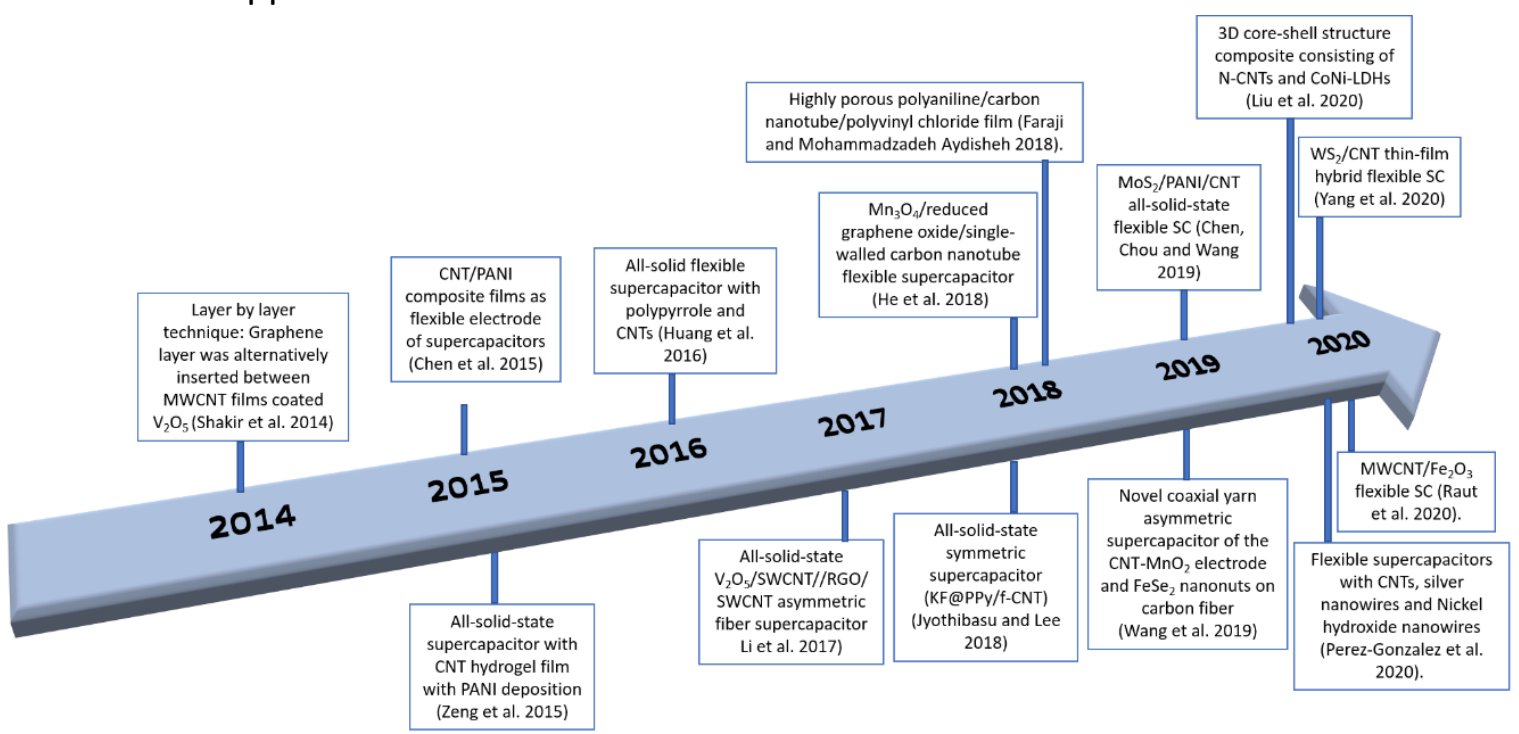

Figure 5: Timeline of the most relevant works in flexible SCs

CNTs functionalized with transition metal oxides based on manganese, vanadium, tungsten, iron, and nickel are used as electrodes to reduce the detrimental effect on cycling stability, compared to devices with only metal oxide electrodes. Of the various pseudocapacitive 
materials, manganese oxides are promising active electrode materials for SCs due to their remarkable electrochemical capacitance, wide potential range, low cost, and environmental friendliness. Thus, hybrid capacitors with manganese oxides and CNTs have been studied. For instance, He et al. (2018) developed a $\mathrm{Mn}_{3} \mathrm{O}_{4} /$ reduced graphene oxide/single-walled CNT hybrid film ( $\left.\mathrm{Mn}_{3} \mathrm{O}_{4} / \mathrm{RGO} / \mathrm{SWCNT}\right)$ as electrode material with outstanding flexibility, resulting in a flexible SC with an elevated energy density and extensive cycle life. This SC was prepared using hybrid films as electrodes sandwiching the PVA-KOH gel electrolyte between them. The device showed a specific capacitance of $360 \mathrm{mF} \mathrm{cm}{ }^{-2}$, which was maintained after 5000 cycles of charge/discharge. Besides, the SC exhibited excellent mechanical performance and an energy density of $32 \mu \mathrm{W} \mathrm{h} \mathrm{cm} \mathrm{cm}^{-2}$ at a power density of $0.392 \mathrm{~mW} \mathrm{~cm}^{-2}$. Also based on manganese, Wang et al. (2019) constructed a novel coaxial yarn asymmetric SC by assembling a CNT-MnO 2 electrode scrolled and twisted together with a negative electrode composed of $\mathrm{FeSe}_{2}$ nanonuts on carbon fiber. The electrodes were coated with the PVA/LiCl gel electrolyte. The SC displayed remarkable flexibility and extensive service life with an energy density of $27.14 \mathrm{~W} \mathrm{~h} \mathrm{~kg}^{-1}$ at a power density of $571.3 \mathrm{~W} \mathrm{~kg}^{-1}$.

Vanadium oxides have also been the focus of study for SC applications, as they give rise to various oxidation states able to operate in a wide range of redox reactions. However, electrochemical SCs based on vanadium oxide $\left(\mathrm{V}_{2} \mathrm{O}_{5}\right)$ with nanostructured networks have quite low energy densities due to their small surface area and low electrical conductivity. In order to solve these problems, Shakir et al. (2014) explored a layer-by-layer (LBL) assembly technique in which a graphene layer was alternatively placed between ultrathin $\mathrm{V}_{2} \mathrm{O}_{5}$ anchored multi-walled carbon nanonotube (MWCNT) layers. The layers were assembled in polyester woven fabric substrate, producing a multilayer SC electrode which was then placed in an organic electrolyte $\left(\mathrm{LiClO}_{4}\right)$. This electrode exhibited an outstanding performance with retention of the capacitance superior to $97 \%$ in 5000 cycles and a high energy density of 96 $\mathrm{W} \mathrm{h} \mathrm{Kg}{ }^{-1}$ at a power density of $800 \mathrm{~W} \mathrm{~kg}^{-1}$. In a similar study, $\mathrm{V}_{2} \mathrm{O}_{5}$-SWCNT hybrid fibers were prepared by using the wet-spinning method. These fibers exhibited good electrochemical performance and flexibility. Reduced graphene oxide (RGO)-SWCNT hybrid fibers were also arranged by a similar wet-spinning process using an aqueous solution of hydriodic acid followed by reduction of graphene oxide precursor (GO). All-solid-state asymmetric $\mathrm{V}_{2} \mathrm{O}_{5} / \mathrm{SWCNT//RGO/SWCNT}$ fiber SCs were assembled with $\mathrm{V}_{2} \mathrm{O}_{5}-\mathrm{SWCNT}$ fiber as the positive electrode, RGO-SWCNT fiber as the negative electrode and using $\mathrm{PVA}^{-} \mathrm{H}_{3} \mathrm{PO}_{4}$ as the electrolyte. Each fiber was coated with $\mathrm{PVA}-\mathrm{H}_{3} \mathrm{PO}_{4}$ gel. After drying, the resulting two fiber electrodes were then twisted together and then coated with an additional layer of the equal gel electrolyte to prevent short-circuit. The assembled device exhibited an energy density of $1.95 \mathrm{~mW} \mathrm{~h} \mathrm{~cm}^{-3}$ at a power density of $7.5 \mathrm{~mW} \mathrm{~cm}^{-3}$, capacitance retention of $74 \%$, and good cycling stability ( $90 \%$ of retention after 3000 cycles). Its flexibility to tolerate repeated and long-term blending was also notable (Li et al. 2017).

Still following the use of CNTs combined with metal oxides as electrode material, a solid-state symmetric SC device was prepared by using $\mathrm{MWCNT} / \mathrm{Fe}_{2} \mathrm{O}_{3}$ electrodes using a flexible stainless steel substrate, with PVA-lithium chloride gel as electrolyte sandwiched between the electrodes. This SC showed a specific capacitance of $70.16 \mathrm{~F} \mathrm{~g}^{-1}$ with retention of $75 \%$ after 1500 cycles, and a remarkable energy density $\left(9.74 \mathrm{~W} \mathrm{~h} \mathrm{~kg}^{-1}\right)$ and power density $\left(487 \mathrm{~W} \mathrm{~kg}^{-1}\right.$ ) at a current density of $0.57 \mathrm{~A} \mathrm{~g}^{-1}$ (Raut et al. 2020). On the other hand, flexible asymmetric SCs have been also reported. Perez-Gonzalez et al. (2020) prepared anodes from CNTs, silver nanowires (Ag NWs), and nickel hydroxide nanowires ( $\left.\mathrm{Ni}(\mathrm{OH})_{2} \mathrm{NWs}\right)$, and cathodes from $\mathrm{CNTs} /$ polyurethane plastic. The most promising SC device $(\mathrm{CN}-\mathrm{Ag} / \mathrm{Ni})$ showed a capacitance 
of $888.6 \mathrm{~F} \mathrm{~g}^{-1}$ and energy density and power density values of $177.3 \mathrm{Wh} \mathrm{kg}^{-1}$ and $27.1 \mathrm{~W} \mathrm{~kg}^{-1}$, respectively. The presence of all these compounds played a key role since they acted as active centers for the redox reactions that contribute to store the charge (Perez-Gonzalez et al. 2020).

2D-type tungsten disulfide $\left(W_{2}\right)$ has been also explored as active material in flexible electrodes due to its similarity with graphene nanostructure and unique chemical and physical properties. WS $\mathrm{W}_{2}$ exhibits low electrical conductivity, so CNTs should be introduced to improve the conductivity. Yang et al. (2020) prepared WS ${ }_{2} @ C N T$ hybrid films by a self-assembly method through vacuum filtration to construct an exceptional skeleton structure that showed great mechanical properties and good electrochemical behavior. The flexible SC was prepared using PVA $/ \mathrm{H}_{2} \mathrm{SO}_{4}$ as electrolyte. The device exhibited a high specific capacitance of $574.65 \mathrm{mF}$ $\mathrm{cm}^{-2}$, an energy density of $0.0798 \mathrm{mWh} \mathrm{cm}^{-2}$ and a power density of $5.745 \mathrm{~mW} \mathrm{~cm}^{-2}$ (Yang et al. 2020). On the other hand, $\mathrm{MoS}_{2}$-based composites are also promising candidates for developing low-cost SCs with high performance. MoS $2 / P A N I / C N T$ composite paper was assembled with sandwich-type using $\mathrm{PVA}-\mathrm{H}_{2} \mathrm{SO}_{4}$ gel as electrolyte. This device exhibited notable energy density $\left(0.013 \mathrm{~W} \mathrm{~h} \mathrm{~cm}^{-3}\right)$ and power density $\left(1.0 \mathrm{~W} \mathrm{~cm}^{-3}\right)$ and was more efficient compared to commercially existing lithium thin-film batteries and activated carbon electrochemical capacitors (Chen, Chou, and Wang 2019).

The introduction of heteroatoms such as nitrogen into CNT structures has also been shown as an interesting strategy to improve the specific capacitance of flexible SCs. Liu et al. (2020) developed a 3D core-shell structure composite consisting of N-CNTs (nitrogen-doped carbon nanotubes) as the core and CoNi-LDHs (layered double hydroxides) as the shell. Due to the introduction of N-CNTs and 3D core-shell structure, the optimized electrode exhibited a larger specific surface area, a stable structure and excellent electrical conductivity. The assembled all-solid-state asymmetric SC, using N-CNTs@ $\mathrm{Co}_{2} \mathrm{Ni}_{1}-\mathrm{LDH}$ and honeycomb porous carbon (HPC) as the positive and negative electrodes, respectively, displayed a high energy density of $51.3 \mathrm{~W} \mathrm{~h} \mathrm{~kg}^{-1}$, a power density of $32 \mathrm{~kW} \mathrm{~kg}^{-1}$, and notable electrochemical stability (92\% retention after 10000 cycles) in PVA/KOH gel electrolyte.

The addition of conducting polymers like polyaniline (PANI), polypyrrole (PPy), or polyvinyl alcohol (PVA) by coating deposition into CNT films is another promising strategy. These polymers were simply grown on CNT film providing higher electrochemical and mechanical performances. While PANI results in pseudocapacitance, PVA matrixes offer bendability and stretchability in flexible SCs. Electrochemical polymerization was used to synthesize PANI nanostructures. The introduction of CNTs into this procedure allowed fabricating CNT/PANI composite films as flexible electrodes for SCs (Chen et al. 2015). Similarly, composite films were obtained by in situ polymerization of PANI on the surface of PVA/CNT films. The PVA/CNT/PANI flexible film exhibited excellent electrochemical performance and flexibility in a PVA $/ \mathrm{H}_{2} \mathrm{SO}_{4}$ gel electrolyte. The device with sandwich configuration achieved a capacitance of $196.5 \mathrm{mF} \mathrm{cm} \mathrm{cm}^{-2}$ with significant cycling stability (5000 cycles) (Ben et al. 2020). Zeng et al. (2015) also assembled an all-solid-state SC using CNT/PANI film as electrodes. The device exhibited an elevated specific capacitance of $184.6 \mathrm{mF} \mathrm{cm} \mathrm{cm}^{-2}$ at $1 \mathrm{~mA} \mathrm{~cm}{ }^{-2}$, which was retained after 500 charge/discharge cycles. Similarly, highly porous PANI-CNTs-PVC films were synthesized by a facile and low-cost strategy and used as electrodes for flexible SCs with improved performance. The flexible PANI-CNTs-PVC SC exhibited a capacitance of $298 \mathrm{mF} \mathrm{cm}^{-}$ ${ }^{2}$ with $86.5 \%$ retention after 5000 cycles at a current density of $0.6 \mathrm{~mA} \mathrm{~cm}^{-2}$ (Faraji and Mohammadzadeh Aydisheh 2018). 
Regarding PPy, Huang et al. (2016) fabricated an all-solid flexible SC based on CNTs and PPy electrode materials and cotton fabric as substrate. The electrodes were obtained by a facile "dipping and drying" method in which CNTs were coated onto the fabric, and then, the PPy was directly electrochemically polymerized onto the CNTs. $\mathrm{PVA}-\mathrm{H}_{3} \mathrm{PO}_{4}$ was used as electrolyte and the flexible SC showed a specific capacitance of $50.09 \mathrm{mF} \mathrm{cm}{ }^{-2}$ and outstanding flexibility. The energy and power densities were $64.64 \mathrm{Wh} \mathrm{kg}^{-1}$ and $5.14 \mathrm{~kW} \mathrm{~kg}^{-1}$, respectively. PPy was also used by Jyothibasu and Lee (2018) to develop an assembled all-solid-state symmetric SC. The electrodes were prepared using PPy-coated kapok fiber (KF) blended with carboxylated CNTs ( $\mathrm{f}-\mathrm{CNT}$ ) as electrodes and PVA/ $\mathrm{H}_{2} \mathrm{SO}_{4}$ gel as electrolyte. This $\mathrm{SC}$ exhibited a high specific capacitance of $258 \mathrm{mF} \mathrm{cm}{ }^{-2}$ at a scan rate of $5 \mathrm{mV} \mathrm{s}^{-1}$, an energy density of $22.3 \mu \mathrm{W} \mathrm{h} \mathrm{cm} \mathrm{cm}^{-2}$, a power density of $0.21 \mathrm{~mW} \mathrm{~cm}^{-2}$ and exceptional cycling stability (97.4\% retention after 2500 cycles). The values of energy and power density of all these promising studies focused on CNTs for flexible SCs are summarized in Table 1.

\begin{tabular}{|c|c|c|c|c|}
\hline Flexible supercapacitor & Electrolyte & $\begin{array}{l}\text { Energy } \\
\text { density }\end{array}$ & $\begin{array}{l}\text { Power } \\
\text { density }\end{array}$ & Ref. \\
\hline $\mathrm{Mn}_{3} \mathrm{O}_{4} / \mathrm{RGO} / \mathrm{SWCNT}$ & PVA-KOH & 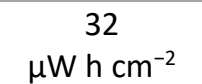 & $\begin{array}{c}0.392 \mathrm{~mW} \\
\mathrm{~cm}^{-2}\end{array}$ & He et al. (2018) \\
\hline $\begin{array}{l}\text { Coaxial yarn asymmetric SC (CNT- } \\
\left.\mathrm{MnO}_{2} / \mathrm{FeSe}_{2}\right)\end{array}$ & PVA-LiCl & $\begin{array}{c}27.14 \\
W \mathrm{~h} \mathrm{~kg}^{-1}\end{array}$ & $\begin{array}{c}571.3 \\
W k^{-1}\end{array}$ & Wang et al. (2019) \\
\hline $\begin{array}{l}\text { Graphene- } \mathrm{V}_{2} \mathrm{O}_{5} \text { anchored } \\
\text { MWCNT layers }\end{array}$ & $\mathrm{LiClO}_{4}$ & $\begin{array}{c}96 \\
\text { W h Kg-1 }\end{array}$ & $\begin{array}{c}800 \\
W k^{-1}\end{array}$ & Shakir et al. (2014) \\
\hline $\mathrm{V}_{2} \mathrm{O}_{5} / \mathrm{SWCNT} / / \mathrm{RGO} / \mathrm{SWCNT}$ & $\mathrm{PVA}-\mathrm{H}_{3} \mathrm{PO}_{4}$ & $\begin{array}{c}1.95 \\
\mathrm{~mW} \mathrm{~h} \mathrm{~cm}^{-3}\end{array}$ & $\begin{array}{c}7.5 \\
\mathrm{~mW} \mathrm{~cm}^{-3}\end{array}$ & Li et al. (2017) \\
\hline $\mathrm{MWCNT} / \mathrm{Fe}_{2} \mathrm{O}_{3}$ & PVA-LiCl & $\begin{array}{c}9.74 \\
\text { W h kg }\end{array}$ & $\begin{array}{c}487 \\
W k^{-1}\end{array}$ & Raut et al. (2020) \\
\hline $\mathrm{CN}-\mathrm{Ag} / \mathrm{Ni}$ & $\begin{array}{c}\text { PMMA, } \\
\text { acetone, } \\
\text { water, } \mathrm{H}_{3} \mathrm{PO}_{4}\end{array}$ & $\begin{array}{c}177.3 \\
\text { Wh kg-1 }\end{array}$ & $\begin{array}{c}27.1 \\
W k^{-1}\end{array}$ & $\begin{array}{l}\text { Perez-Gonzalez et al. } \\
\qquad(2020)\end{array}$ \\
\hline WS $@$ @NT & PVA- $\mathrm{H}_{2} \mathrm{SO}_{4}$ & $\begin{array}{c}0.0798 \mathrm{mWh} \\
\mathrm{cm}^{-2}\end{array}$ & $\begin{array}{l}5.745 \mathrm{~mW} \\
\mathrm{~cm}^{-2}\end{array}$ & Yang et al. (2020) \\
\hline $\mathrm{MoS}_{2} / \mathrm{PANI} / \mathrm{CNT}$ & $\mathrm{PVA}-\mathrm{H}_{2} \mathrm{SO}_{4}$ & $\begin{array}{c}0.013 \\
\mathrm{Wh} \mathrm{cm}^{-3}\end{array}$ & $\begin{array}{c}1.0 \\
W \mathrm{~cm}^{-3}\end{array}$ & $\begin{array}{l}\text { Chen, Chou, and Wang } \\
\text { (2019) }\end{array}$ \\
\hline N-CNTs@Co $2 \mathrm{Ni}_{1}-\mathrm{LDH} / / \mathrm{HPC}$ & PVA-KOH & $\begin{array}{c}51.3 \\
\text { Wh kg }\end{array}$ & $\begin{array}{c}32 \\
k W k^{-1}\end{array}$ & Liu et al. (2020) \\
\hline CNTs/PPy & PVA- $\mathrm{H}_{3} \mathrm{PO}_{4}$ & $\begin{array}{c}64.64 \\
W_{h ~ k g}\end{array}$ & $\begin{array}{c}5.14 \\
k W k^{-1}\end{array}$ & Huang et al. (2016) \\
\hline KF@PPy/f-CNT & $\mathrm{PVA} / \mathrm{H}_{2} \mathrm{SO}_{4}$ & $\begin{array}{c}22.3 \\
\mu \mathrm{W} \mathrm{h} \mathrm{cm}\end{array}$ & $\begin{array}{c}0.21 \\
\mathrm{~mW} \mathrm{~cm}\end{array}$ & $\begin{array}{l}\text { Jyothibasu and Lee } \\
\text { (2018) }\end{array}$ \\
\hline
\end{tabular}

Table 1: Summary of studies on CNTs in flexible SCs

\section{Conclusions and Future Challenges}

CNTs are very promising materials for applications toward energy conversion and storage owing to their exceptional features such as high electrical conductivity, electron mobility, and mechanical strength. CNTs as electrode material and gel polymers as electrolyte are reported as an excellent combination for flexible SCs. The recent developments suggest that growing the charge carrier concentration and combining redox-active materials such as metal oxides, sulfides, or conductive polymers with CNTs improve ionic conductivity and enhance the mechanical properties, making them appropriate as high-performance electrodes for use in flexible solid-state SCs, and meeting the needs of modern society. 


\section{References}

Alipoori, S., S. Mazinani, S. H. Aboutalebi, and F. Sharif. 2020. "Review of PVA-based gel polymer electrolytes in flexible solid-state supercapacitors: Opportunities and challenges". Journal of Energy Storage 27 (february): Article number 101072. https://doi.org/10.1016/j.est.2019.101072.

Aziz, S. B., T. J. Woo, M. F. Z. Kadir, and H. M. Ahmed. 2018. "A conceptual review on polymer electrolytes and ion transport models". Journal of Science: Advanced Materials and Devices 3, no. 1 (march): 1-17. https://doi.org/10.1016/j.jsamd.2018.01.002.

Beidaghi, M., and Y. Gogotsi. 2014. "Capacitive energy storage in micro-scale devices: recent advances in design and fabrication of micro-supercapacitors". Energy \& Environmental Science 7, no. 3 (march): 867-84. https://doi.org/10.1039/C3EE43526A.

Ben, J., Z. Song, X. Liu, W. Lü, and X. Li. 2020. "Fabrication and electrochemical performance of PVA/CNT/PANI flexible films as electrodes for supercapacitors". Nanoscale Research Letters 15, no. 1: Article number 151. https://doi.org/10.1186/s11671-020-03379-w.

Chen, H., S. Zeng, M. Chen, Y. Zhang, and Q. Li. 2015. "Fabrication and functionalization of carbon nanotube films for high-performance flexible supercapacitors". Carbon 92 (july): 271-96. https://doi.org/10.1016/j.carbon.2015.04.010.

Chen, I.-W. P., Y.-C. Chou, and P.-Y. Wang. 2019. "Integration of ultrathin MoS2/PANI/CNT composite paper in producing all-solid-state flexible supercapacitors with exceptional volumetric energy density". The Journal of Physical Chemistry C 123, no. 29 (july): 1786472. https://doi.org/10.1021/acs.jpcc.9b04046.

Choudhary, N., C. Li, J. Moore, N. Nagaiah, L. Zhai, Y. Jung, and J. Thomas. 2017. "Asymmetric supercapacitor electrodes and devices". Advanced Materials 29, no. 21 (june): Article number 1605336. https://doi.org/10.1002/adma.201605336.

Choudhury, N. A., S. Sampath, and A. K. Shukla. 2009. "Hydrogel-polymer electrolytes for electrochemical capacitors: An overview". Energy and Environmental Science 2, no. 1: 5567. https://doi.org/10.1039/b811217g.

Choudhury, N. A., A. K. Shukla, S. Sampath, and S. Pitchumani. 2006. "Cross-linked polymer hydrogel electrolytes for electrochemical capacitors". Journal of The Electrochemical Society 153, no. 3: A614-A20. https://doi.org/10.1149/1.2164810.

Dey, R. S., and D. Kumar. 2016. "Carbonaceous materials for next-generation flexible supercapacitors". Reviews in Advanced Sciences and Engineering 5, no. 1 (march): 32-50. https://doi.org/10.1166/rase.2016.1106.

Faraji, M., and H. Mohammadzadeh Aydisheh. 2018. "Rational synthesis of a highly porous PANI-CNTs-PVC film for high performance flexible supercapacitor". ChemElectroChem 5, no. 19 (october): 2882-92. https://doi.org/10.1002/celc.201800628.

Frackowiak, E. 2007. "Carbon materials for supercapacitor application". Physical Chemistry Chemical Physics 9, no. 15: 1774-85. https://doi.org/10.1039/B618139M.

He, J., D. Yang, H. Li, X. Cao, L. Kang, X. He, R. Jiang, J. Sun, Z. Lei, and Z.-H. Liu. 2018. "Mn304/RGO/SWCNT hybrid film for all-solid-state flexible supercapacitor with high energy density". Electrochimica Acta 283 (september): 174-82. https://doi.org/10.1016/j.electacta.2018.06.162.

Huang, S., P. Chen, W. Lin, S. Lyu, G. Chen, X. Yin, and W. Chen. 2016. "Electrodeposition of polypyrrole on carbon nanotube-coated cotton fabrics for all-solid flexible supercapacitor electrodes". RSC Advances 6, no. 16: 13359-64. https://doi.org/10.1039/C5RA24214B. 
J. Varma, S., K. Sambath Kumar, S. Seal, S. Rajaraman, and J. Thomas. 2018. "Fiber-type solar cells, nanogenerators, batteries, and supercapacitors for wearable applications". Advanced Science 5, no. 9 (september): Article number 1800340. https://doi.org/10.1002/advs.201800340.

Jyothibasu, J. P., and R.-H. Lee. 2018. "Facile, scalable, eco-friendly fabrication of highperformance flexible all-solid-state supercapacitors". Polymers 10, no. 11 (november): Article number 1247. https://doi.org/10.3390/polym10111247.

Kumar, S., M. Nehra, D. Kedia, N. Dilbaghi, K. Tankeshwar, and K.-H. Kim. 2017. "Carbon nanotubes: A potential material for energy conversion and storage". Progress in Energy and Combustion Science 64: 219-53. https://doi.org/10.1016/j.pecs.2017.10.005.

Li, H., J. He, X. Cao, L. Kang, X. He, H. Xu, F. Shi, R. Jiang, Z. Lei, and Z.-H. Liu. 2017. "All solidstate V2O5-based flexible hybrid fiber supercapacitors". Journal of Power Sources 371 (december): 18-25. https://doi.org/10.1016/j.jpowsour.2017.10.031.

Liu, C., F. Li, L.-P. Ma, and H.-M. Cheng. 2010. "Advanced materials for energy storage". Advanced Materials 22, no. 8: E28-E62. https://doi.org/10.1002/adma.200903328.

Liu, R., Y. Wang, S. Sun, C. Chen, and X. Wu. 2020. "CoNi layered double hydroxide anchored on $\mathrm{N}$-doped carbon coated carbon nanotubes network with 3D Core-shell structure for allsolid-state supercapacitors". Journal of Electroanalytical Chemistry 878 (december): Article number 114571. https://doi.org/10.1016/j.jelechem.2020.114571.

Lota, G., K. Fic, and E. Frackowiak. 2011. "Carbon nanotubes and their composites in electrochemical applications". Energy \& Environmental Science 4, no. 5 (may): 1592-605. https://doi.org/10.1039/COEE00470G.

Meng, C., O. Z. Gall, and P. P. Irazoqui. 2013. "A flexible super-capacitive solid-state power supply for miniature implantable medical devices". Biomedical Microdevices 15, no. 6 (december): 973-83. https://doi.org/10.1007/s10544-013-9789-1.

Miller, J. R., and A. F. Burke. 2008. "Electrochemical capacitors: Challenges and opportunities for real-world applications". Electrochemical Society Interface 17, no. 1 (march): 53-57. https://doi.org/10.1149/2.F08081IF.

Pereira, C., and A. M. Pereira. 2016. "Functional carbon-based nanomaterials for energy storage: Towards smart textile supercapacitors". Boletin Del Grupo Espanol Del Carbon no. 40: 42-48. http://www.gecarbon.org/boletines/articulos/BoletinGEC_040-art8.pdf.

Perez-Gonzalez, R., E. Araujo, W. Ge, S. Cherepanov, A. Zakhidov, V. Rodriguez-Gonzalez, A. Encinas, and J. Oliva. 2020. "Carbon nanotube anodes decorated with $\mathrm{Ag} \mathrm{NWs/Ni(OH)2}$ NWs for efficient semitransparent flexible solid state supercapacitors". Electrochimica Acta 354: Article number 136684. https://doi.org/10.1016/j.electacta.2020.136684.

Raut, S. S., L. K. Bommineedi, S. Pande, and B. R. Sankapal. 2020. "Prototype symmetric configured MWCNTs/Fe2O3 based solid-state supercapacitor". Synthetic Metals: 116629. Article in press. https://doi.org/10.1016/j.synthmet.2020.116629.

Segawa, Y., H. Ito, and K. Itami. 2016. "Structurally uniform and atomically precise carbon nanostructures". Nature Reviews Materials 1, no. 1 (january): Article number 15002. https://doi.org/10.1038/natrevmats.2015.2.

Shakir, I., Z. Ali, J. Bae, J. Park, and D. J. Kang. 2014. "Layer by layer assembly of ultrathin V2O5 anchored MWCNTs and graphene on textile fabrics for fabrication of high energy density flexible supercapacitor electrodes". Nanoscale 6, no. 8 (april): 4125-30. https://doi.org/10.1039/C3NR06820J. 
Thakur, V. K., G. Ding, J. Ma, P. S. Lee, and X. Lu. 2012. "Hybrid materials and polymer electrolytes for electrochromic device applications". Advanced Materials 24, no. 30 (august): 4071-96. https://doi.org/10.1002/adma.201200213.

Tu, Q.-M., L.-Q. Fan, F. Pan, J.-L. Huang, Y. Gu, J.-M. Lin, M.-L. Huang, Y.-F. Huang, and J.-H. Wu. 2018. "Design of a novel redox-active gel polymer electrolyte with a dual-role ionic liquid for flexible supercapacitors". Electrochimica Acta 268: 562-68. https://doi.org/10.1016/j.electacta.2018.02.008.

Vandana, M., H. Vijeth, S. P. Ashokkumar, and H. Devendrappa. 2020. "Effect of different gel electrolytes on conjugated polymer - Graphene quantum dots based electrode for solid state hybrid supercapacitors". Polymer-Plastics Technology and Materials 59, no. 18: 206875. https://doi.org/10.1080/25740881.2020.1784221.

Wang, Q., Y. Ma, X. Liang, D. Zhang, and M. Miao. 2019. "Flexible supercapacitors based on carbon nanotube-MnO2 nanocomposite film electrode". Chemical Engineering Journal 371 (september): 145-53. https://doi.org/10.1016/j.cej.2019.04.021.

Wen, L., F. Li, and H.-M. Cheng. 2016. "Carbon nanotubes and graphene for flexible electrochemical energy storage: From materials to devices". Advanced Materials 28, no. 22 (june): 4306-37. https://doi.org/10.1002/adma.201504225.

Winter, M., and R. J. Brodd. 2004. "What are batteries, fuel cells, and supercapacitors?". Chemical Reviews 104, no. 10 (october): 4245-69. https://doi.org/10.1021/cr020730k.

Yang, Y. 2020. "A mini-review: Emerging all-solid-state energy storage electrode materials for flexible devices". Nanoscale 12, no. 6: 3560-73. https://doi.org/10.1039/C9NR08722B.

Yu, M., T. Zhai, X. Lu, X. Chen, S. Xie, W. Li, C. Liang, W. Zhao, L. Zhang, and Y. Tong. 2013. "Manganese dioxide nanorod arrays on carbon fabric for flexible solid-state supercapacitors". Journal of Power Sources 239: 64-71. https://doi.org/10.1016/j.jpowsour.2013.03.083.

Zeevi, G., M. Shlafman, T. Tabachnik, Z. Rogachevsky, S. Rechnitz, I. Goldshtein, S. Shlafman, et al. 2016. "Automated circuit fabrication and direct characterization of carbon nanotube vibrations". Nature Communications 7 (july): Article number 12153. https://doi.org/10.1038/ncomms12153.

Zeng, S., H. Chen, F. Cai, Y. Kang, M. Chen, and Q. Li. 2015. "Electrochemical fabrication of carbon nanotube/polyaniline hydrogel film for all-solid-state flexible supercapacitor with high areal capacitance". Journal of Materials Chemistry A 3, no. 47: 23864-70. https://doi.org/10.1039/C5TA05937B.

Zhai, Y., Y. Dou, D. Zhao, P. Fulvio, R. Mayes, and S. Dai. 2012. "Carbon materials for chemical capacitive energy storage". Advanced Materials 23: 4828-50. https://doi.org/10.1002/adma.201100984.

Zhao, C., X. Jia, K. Shu, C. Yu, G. G. Wallace, and C. Wang. 2020. "Conducting polymer composites for unconventional solid-state supercapacitors". Journal of Materials Chemistry A 8, no. 9 (march): 4677-99. https://doi.org/10.1039/C9TA13432H.

Zhao, X., B. M. Sánchez, P. J. Dobson, and P. S. Grant. 2011. "The role of nanomaterials in redox-based supercapacitors for next generation energy storage devices". Nanoscale 3, no. 3 (march): 839-55. https://doi.org/10.1039/C0NR00594K.

Zhong, C., Y. Deng, W. Hu, J. Qiao, L. Zhang, and J. Zhang. 2015. "A review of electrolyte materials and compositions for electrochemical supercapacitors". Chemical Society Reviews 44, no. 21 (november): 7484-539. https://doi.org/10.1039/C5CS00303B. 
Zhu, S., J. Ni, and Y. Li. 2020. "Carbon nanotube-based electrodes for flexible supercapacitors". Nano Research 13, no. 7 (july): 1825-41. https://doi.org/10.1007/s12274-020-2729-5.

\section{Acknowledgments}

This work was funded by FEDER - European Regional Development Fund through COMPETE 2020-Operacional Programme for Competitiveness and Internationalization (POCI) and by Portuguese funds through Fundacão para a Ciência e a Tecnologia (FCT)/MCTES under Program PT2020 in the framework of the projects PTDC/CTM-TEX/31271/ 2017, UIDB/50006/2020 and UIDB/04968/2020. 